\title{
A Study of Various classes of police officers in the traffic division of Ahmedabad and their Work Stress/Anxiety/Worry
}

\author{
Mehul Mahendrabhai Patel*
}

\section{ABSTRACT:}

The following study was conducted to study the work related stress and its effect on the police officers working in the traffic division of Ahmedabad city, Gujarat, India. For this the sample selected was Constables and Head Constables who held an experience of 1-5 years of duty (60 samples) and 10-15 years of duty (60 samples). The total samples in the population was 120 $(\mathrm{N}=120)$. The samples were selected from a variety of regions throughout the city of Ahmedabad. To measure the job related stress, the Job Stress Scale was used which was developed by A. K. Shrivastava and M. M. Sinha. The psychometric method used for statistical analysis was the ' $\mathrm{t}$ ' test. The study showed that the second group (10-15 years experience) showed less work related stress than the first group (1-5 years experience); in both the classes of officers, that is, constables and head constables.

Keywords: Stress, Anxiety, Worry, Police officers, Ahmedabad City

\section{INTRODUCTION}

People often refer to this age as the age of stress. In psychological terms, stress is a manifestation of Anxiety. The origin of the word Anxiety is rooted in the Latin word Augustus. Anxiety and fear are related. In 1994 Kessler proposed, through his research, that anxiety can be a part of a mental disturbance and it is a fairly common occurrence as far as mental health is concerned. Its prevalence is about $19 \%$ in Males and $31 \%$ in females.

Different psychologists have tried to define anxiety and stress in a variety of manner and perspectives. Anxiety is an unpleasant state of inner turn oil, often accompanied by nervous behavior, such as pacing back and forth, somatic complaints and rumination. It is the subjectively unpleasant feelings of dread over anticipated events. Anxiety usually always has to do with what 'may' happen in the coming future.

\section{Types:}

Anxiety is a feeling of fear, worry, and uneasiness, usually generalized and unfocused as an overreaction to a situation that is only subjectively seen as menacing. As far as mental health is concerned, anxiety can manifest in a variety of forms. Some of these are test anxiety, social anxiety, sexual anxiety and so on.

*M. Phil, School Of Psychology, Gujarat University

(C) 2014 Mehul; licensee IJIP. This is an Open Access Research distributed under the terms of the Creative Commons Attribution License (http://creativecommons.org/licenses/by/2.0), which permits unrestricted use, distribution, and reproduction in any Medium, provided the original work is properly cited. 


\section{A Study of Various classes of police officers in the traffic division of Ahmedabad and their Work Stress/Anxiety/Worry}

According to Freud, a feeling of impending danger that can be based on objective, neurotic, or moral threats.

\section{Factors:}

Anxiety can arise from a variety of factors.

Kleppner and Cube say that when there is a vast gap between a persons desire or situation and his goals then he can be threatened by a state of anxiousness.

Anxiety is in a way a biological instinct of man so that he can focus to the problem at hand and can actively deal and alleviate it.

Parents who are constantly in an anxious state of mind tend transfer this trait to their offsprings as well. If parents expect too much out of their kids, and if the kid is unable to fulfill these expecation then he can face these anxiety and stress as well.

Anxiety often roots out of the biological instinct of survival and the challenges faced by a person in his life and in a way it forms an important motivational tool. However if the individual cannot find effective ways to cope with this stress then he may face problems due to the anxiety itself which hinders his cognition and ability to deal with real-life issues.

\section{Previous Researches:}

1) A Study on Job Related Anxiety/Stress and Mental health of Mahrashtra Police Constables; Barve B.N., Indian Streams Research Journal, November 2011.

The study focused on finding out job related stress of 100 male and 100 female constables of the Maharashtra Police. Their mental health was measured and it was found that there is a difference in the stress of job felt by men and women.

2) Nilofar Ehsaan and Jean Abdul (2009), A Study of Malaysian University Staff and their Job Satisfaction \& Job stress. The study was done on a sample of employees of public universities of Malaysia. It was found that there is a correlation between the Job Stress and Job Satisfaction.

3) McLean (1974); Cooper and Marshall (1976); Brick, Schuller \& Wansel (1981) proposed that work overload, work related role and role confusion can be major factors in affecting job related stress or anxiety.

Penn (1981) found out that the major factor which is the cause of work stress can be found in the environment and surroundings of the work. This can also include collegues in our work area. For instance sometimes bosses expect more than an employee may be capable of. 


\section{A Study of Various classes of police officers in the traffic division of Ahmedabad and their Work Stress/Anxiety/Worry}

\section{AIM OF THE RESEARCH:}

To study the factors of work related stress presenting in Constables and Head Constables holding a work experience of 1-5 years (Group 1) and 10-15 years (Group 2.)

\section{NULL HYPOTHESIS:}

There is no difference in the work related stress between the two groups; Group 1 being constables and head constables having work experience of 1-5 years and Group 2 being constables and head constables with 10-15 years of work experience.

\section{Independent Variable:}

The Occupational Stress Index (OCI) presented to measure job stress.

\section{Dependent Variables:}

There were 2 dependent variable

1) The score on OCI for constables and head constables with traffic duty experience of 1 to 5 years (Group 1)

2) The score on OCI for constables and head constables with traffic duty experience of 10-15 years (Group 2)

\section{DESIGN:}

The following study used a non-repeated measures design of sample and a two-tailed 't' test was used to measure the variance between the two groups. That is a subject was exposed to only one of the two groups in the study.

\section{METHOD:}

Keeping in mind the aim of the study, the samples were selected from a variety of regions in the city of Ahmedabad city like Shaahibaug, CTM, Maninagar, Iisanpur, Satellite, Navrangpura, Ghatlodiya, Nehru Nagar, Naroda, etc. The samples selected were divided into 2 groups. Group 1 was constables and head constables holding a traffic duty experience of 1-5 years and Group 2 was constables and head constables holding a traffic duty experience of 10-15 years. There were a total of 120 samples selected from the overall population and were selected at random. <One line cannot translate. Check!!!>

\section{Tools \& Apparatus:}

1. Job Stress Scale (A. K. Shrivastava \& Dr. M. M. Sinha) consisting of 80 items. These 80 items have been sorted into 7 different categories.

The test ideally takes about 20-25 minutes to finish. 


\section{A Study of Various classes of police officers in the traffic division of Ahmedabad and their Work Stress/Anxiety/Worry}

The split half reliability coefficient of the test is 0.85 and test-test reliability was found out to be 0.81 . The validity was checked by comparing it to Rolf Analysis Form (1961), and was found out to be 0.54. On top of that it was also compared to the Sarsen's General Anxiety Test (1957) and was found to be 0.56.

\section{Analysis of Data:}

There is a significant difference between the values obtained for job related stress and anxiety between the Group 1 (Constables/Head-Constables with 1-5 years experience) and Group 2 (Constables/HeadConstables with 10-15 years experience.)

\begin{tabular}{|l|l|l|l|l|l|}
\hline Categories & \multicolumn{1}{|c|}{$\mathrm{N}$} & $\mathrm{M}$ & $\mathrm{SD}$ & 't' Value & $\mathrm{S} 0.05$ \\
\hline 1 to 5 years & 30 & 41.2 & 4.84 & & \\
\hline 10 to 15 years & 30 & 32.2 & 6.91 & & $\mathrm{~S}$ \\
& & & & & \\
\hline
\end{tabular}

$\mathrm{S}=$ Significant $\&$ N.S.= Non-Significant

\section{RESULTS \& DISCUSSION:}

In the given tables, we can see that the't' value obtained for the job stress for traffic police in the 2 groups is $3.37(\mathrm{p}=0.05)$. The mean obtained for traffic police constable and head constables who have been in the field for $1-5$ years is $41.2(\mathrm{SD}=4.84)$. Whereas the mean for constables and head constables with work experience of $10-15$ years is $32.2(\mathrm{SD}=6.91)$.

Here we can say that the stress felt by people in Group 1 is more than that of those included in Group 2. The reason for this difference could be that the people in Group 1 have to get used to a new way or method of working in their work environment and hence they may face more stress. The stress could also be due to the fact that these individuals are posted in variety of places right after their training and testing. The mental stress can also arise due to inappropriate attitude or approach towards their work environment. When comparing these people with those in Group 2, the Group 2 individuals have been in the field for a lot more time and hence are experienced and comfortable with how the system works and hence they feel less stress and anxiety

\section{REFERENCES AND CITATIONS:}

1) Brake B.N. Nov. (2011) Mumbai (India research streams) "A study of job Anxiety, job Involvement, and mental health on Maharastraiyan police constable.

2) JANSARI ASHVIN AND PRAJAPATI MUKESH PABLISH "INFERNCE STATISTICS-1" WITH “AKSHAR PUBLICETION” IN GUJRAT UNIVERSITY.(2012 - 2013)

3) JAWARS (1971) "Anxiety and Job Satisfaction "Indian Journal of Applied psychology pp. 70-70 (IPS) 53.

4) Srivastava A.K. \& Sinha M.M. (1974) “job Anxiety Scales” Rapa psychological center Varanasi. 